\title{
Etiology and Risk Factors of Lumbar Intervertebral Disc (IVD) Degeneration
}

\author{
Ujjwal K Debnath* \\ Consultant Orthopaedics\& Spine Surgeon, India \\ *Corresponding author: Ujjwal K Debnath, India
}

Submission: 眥 February 26, 2018; Published: 眥 April 24, 2018

\begin{abstract}
Lumbar degenerative disc disease (DDD) is a progressive condition that exists along a continuum of pathologic processes. The disease starts as desiccation of the nucleus pulposus, to annular tearing, diffuse disc bulging, and disc space collapse, the degenerative process can occur over the course of decades, culminating in substantial debilitation. Clinically DDD presents with back pain and/or radiculopathy, can limit work and productivity. Additionally, the cost of treating this condition is especially high, and billions of dollars are spent on managing degenerative spinal processes annually.

In this review, the main focus is on the recent advances in studies on the most extensively examined risk factors and genetic factors associated with DDD in humans. A number of genetic defects have been correlated with structural and functional changes within the intervertebral disc (IVD), which may compromise the disc's mechanical properties and metabolic activities. These studies have begun to shed light on the molecular basis of DDD, suggesting that genetic factors are important contributors to the onset and progression of IDD. By continuing to improve our understanding of the molecular mechanisms of DDD, specific early diagnosis and more effective treatments for this disabling disease may be possible in the future.
\end{abstract}

\section{Introduction}

Over the decades, we have come to appreciate that spinal degeneration involves a complex interplay of biologic and biomechanical events that are predisposed by risk factors i.e. environmental or genetic or lifestyle factors. The prevalence of back pain increases with age and lifetime recurrence is a high a $85 \%$ [1]. Chronic LBP is the most common cause of disability in the 45-65years age group [2]. Some degree of disc degeneration can be observed in most adults [3]. Since LBP has wide spectrum of etiologies, it is generally realized in $20 \%$ patients [4]. The most common cause of LBP who had lumbar disc herniation (LDH) was sprain/strain (48.8\%) in age group of <30years, heavy working $(63.2 \%)$ in those between 30-44years of age, and osteoporosis $(62.8 \%)$ in those $>45$ years of age [5].

\section{Environmental factors}

As discussed earlier, ageing is associated with degeneration of disc but there are other influences of contributing factors. Apart from the physiological stress of ageing there are dynamic stresses leading to DDD. Many patients with LBP have high Body Mass Index (heavy body weight). The disc degeneration has been associated with certain activities (loss of adequate movement, inappropriate movements, lifting of heavy weights, whole body vibration etc.) $[6,7]$. Smoking habit induces biochemical stress to several tissues. Such stress is part of the environmental components contributing to the nutrition and blood flow changes on the disc promoting degeneration. Polycyclic aromatic hydrocarbons in the cigarettes leads to endothelial injuries while carbon monoxide, resulting from combustion reduces the oxygen carrying capacity of red blood cells. There is increase in the catecholamines which results in vasoconstriction leading to reduced oxygen supply to tissues [8].

\section{Biological factors (Table 1)}

Changes in ECM (Extracellular Matrix): Collagen synthesis increases in the initial stages of degeneration with a clear increase in type II Collagen in the NP (maybe indicating repair mechanism) [9]. As the degeneration progresses the synthesis pattern changes and more type II Collagen is synthesized in AF. Type I collagen is synthesized in the deep region of AF and NP. Type X collagen formation is associated with chondrocyte agglomerates and tears of degenerated IVDs. The synthesis of proteoglycans also changes with decline in production of aggrecan and increase in the synthesis of versican, biglycan and decorin. There is reduced Glycosaminoglycans (GAGs) esp. modification of chondroitin sulfate to keratan sulfate. These results in disc desiccation and degeneration [10]. The remodeling of the ECM results from these changes occurring simultaneously. The protagonists of the process are the matrix metallo-proteinases (MMPs) [11]. There are ADAMTS (a desintegrin and metalloproteinase with thrombospondin), which play similar but more powerful roles like MMPs. Both these families have the same endogenous inhibitors called TIMPs (Tissue inhibitor matrix metallo-proteinases), which act synergistically in the remodeling of ECM [12]. 
Table 1: Important molecules involved in IVD ageing and degeneration (Reproduced from Baptista JDS, Fontes RBDV, Liberti EA. Aging and degeneration of the intervertebral disc: review of basic science. Coluna 2015; 14 (2):146).

\begin{tabular}{|c|c|c|c|}
\hline Classification & Molecule & Function & $\begin{array}{l}\text { General Repercussions on old Age } \\
\text { and Infirmity }\end{array}$ \\
\hline \multirow{7}{*}{ Catabolic/Remodelers of ECM } & $\begin{array}{c}\text { MMP-1 } \\
\text { (collagenase -1) }\end{array}$ & Degradation of collagen I,II, III and gelatin & \multirow{5}{*}{$\uparrow \uparrow \uparrow$ act in the remodeling of ECM } \\
\hline & $\begin{array}{l}\text { MMP-3 } \\
\text { (Stromelysin -1) }\end{array}$ & $\begin{array}{l}\text { Degradation of collagen II,III, IV,V,X elastin, } \\
\text { fibronectin, laminin and activation of } \\
\text { other MMPs }\end{array}$ & \\
\hline & $\begin{array}{c}\text { MMP-13 } \\
\text { (collagenase-1) }\end{array}$ & $\begin{array}{l}\text { Degradation of collagen I,II, III,IV, IX, X and } \\
\text { gelatin }\end{array}$ & \\
\hline & ADAMTS-4 (aggrecanase -1) & Degradation of aggrecan & \\
\hline & ADAMTS-5 (aggrecanase -2) & Most powerful degrader of aggrecan & \\
\hline & TIMP -1 & Endogenous inhibitor of MMPs -1 and -3 & \multirow{2}{*}{$\begin{array}{l}\text { Remodeling of ECM, imbalance } \\
\text { between MMPs/ADAMTS and TIMPs } \\
\text { generates degradation of ECM }\end{array}$} \\
\hline & TIMP-3 & $\begin{array}{l}\text { Endogenous inhibitor of ADAMTS }-4 \text { and } \\
-5\end{array}$ & \\
\hline \multirow{3}{*}{ Catabolic/cytokines } & IL-1 $\beta$ & $\begin{array}{l}\text { Regulates immune and inflammatory } \\
\text { response, activates T \& B lymphocytes, } \\
\text { NK cells }\end{array}$ & \multirow{2}{*}{$\begin{array}{l}\text { } \uparrow \uparrow i n \text { degeneration, responsible for } \\
\text { catabolic metabolism }\end{array}$} \\
\hline & TNF- $\alpha$ & $\begin{array}{l}\text { Regulates immune and inflammatory } \\
\text { response, Acts in apoptosis }\end{array}$ & \\
\hline & IL-1Ra (receptor antagonist) & Natural competitor to IL-1 receptors & $\begin{array}{l}\downarrow \downarrow \downarrow \text { esp. in the presence of } \\
\text { degenerative process }\end{array}$ \\
\hline \multirow{3}{*}{ Growth factors } & VEGF & Act in development of endothelial cells & $\begin{array}{c}\text { } \uparrow \uparrow \uparrow \text { in response to a possible repair } \\
\text { mechanism }\end{array}$ \\
\hline & NGF- $\beta$ & $\begin{array}{l}\text { Act in axonogenesis, in the differentiation } \\
\text { of sensory neurons and in neuron } \\
\text { functions mediated by pain and } \\
\text { inflammation }\end{array}$ & \multirow{2}{*}{$\begin{array}{c}\uparrow \uparrow \uparrow \text { stimulate axon growth, are the } \\
\text { possible origin of discogenic pain } \\
\text { or can be considered a structure } \\
\text { protection factor }\end{array}$} \\
\hline & BDNF & $\begin{array}{l}\text { Act in axonogenesis, maintenance of } \\
\text { subpopulations and neuroplasticity }\end{array}$ & \\
\hline
\end{tabular}

\section{Proinflammatory cytokines}

Most important cytokines which influences the IVD degeneration process are Interleukin -1 (IL-1) and Tumor necrosis factor- $\alpha$ (TNF- $\alpha$ ). Large volumes of research and evidence suggest these cytokines are directly or indirectly involved in the process of disc degeneration [13]. It has been shown that IL-1 is produced in the degenerate IVD. It is normally synthesized by the native chondrocyte like cells, but in the non-degenerate IVD there is maintenance of ECM homeostasis due to a balance between IL-1 and its inhibitor IL-1Ra (Interleukin -1 Receptor antagonist). The normal inhibitory mechanism fails in disc degeneration, with loss of balance of IL-1 agonists to antagonists, allowing IL-1 to elicit and perpetuate a response [14]. TNF- $\alpha$ may have limited effects during the IVD degeneration but during disc herniation TNF- $\alpha$ is produced by the cells in the herniated disc. IVD disc comes in contact with the nerve root and inflammatory cells. TNF- $\alpha$ could have a detrimental effect on the local nerves, resulting in generation of LBP and sciatica $[15,16]$.

\section{Matrix degrading enzymes and catabolic mediators}

The two major enzymes involved in IVD degeneration are MMPs and ADAMTS. The homeostasis of ongoing ECM turnover is managed by the balance between MMPs and tissue inhibitors of MMPs [17]. The collagen molecules (I, II \& III) are primarily degraded by MMP-
$1,-8$ and -13 and the denatured collagen is degraded by MMP-2 and MMP-9. Increased expression of MMPs leads to accelerated destruction of ECM. Similarly increase in expression of ADAMTS (esp. ADAMTS- 4 and -5 increases the aggrecan turnover) results in accelerated IVD degeneration [18]. MMP-3 are categorized as stromelysins which degrades proteoglycans, laminas and other components of ECM and indirectly degrades the disc by activating MMPs [18].

\section{Growth factors}

Growth factors, such as transforming growth factor (TGFs), Insulin like Growth factors (ILGF) and basic fibroblast growth factor (FGF) stimulate the chondrocytes or fibroblasts to produce more ECM and inhibit the production of MMPs [19].

Aggrecan (AGC 1): Aggrecan is the major proteoglycan in the NP of the IVD. Its key function is to maintain hydration of the disc structure, attracting water molecules through highly negatively charged GAG moieties which are mainly chondroitin sulfate and keratan sulfate chains that creates an osmotic gradient [20].

Vitamin D receptor (VDR): It is a steroid nuclear receptor involved in bone mineralization and remodeling. Vitamin D can influence sulfate metabolism which is an important influence on sulfation of GAGs during proteoglycan synthesis [21]. 


\section{Angiogenesis factors}

It is currently believed that the presence of Vascular endothelial growth factor (VEGF) in IVDs originates from inflammatory chain (IL-1 $\beta$ and TNF- $\alpha$ in the NP) due to metabolic requirement of the region [22].

Genetic influence on IVD degeneration: The past two decades in genomic research has revealed an astounding number of gene polymorphism of various genes that are correlated with increased risk of developing DDD. Polymorphisms in the genes coding for collagen, aggrecan, interleukins (ILs), apoptosis factors, vitamin D receptor, MMPs and other proteins are implicated [23]. Amongst these genes only the association of degeneration of IVDs are mostly due to polymorphisms in the VDR and COL9A2 genes. These molecules affect the integrity or function of the ECM on the cartilage and is responsible for the mechanical properties of IVDs [24].

Collagen: Collagen Iismore abundant within AF of the IVD. There is increased risk of DDD with COL1A1 Sp1 binding site SNP (Single nucleotide polymorphisms) polymorphism [25,26]. Collagen IX is thought to play an important role in connecting various types of collagens together, particularly collagen type II. Various studies found SNPs located on either COL9A2 or COL9A3 which may be associated with increased risk of DDD [27]. Trp3, a common SNP in COL9A3 has strong association for IVD degeneration [28]. Collagen $\mathrm{XI}$ is present in AF and NP of IVDs serves as connectors between different collagen molecules esp. collagen II and proteoglycan molecules [21]. Research suggests that SNPs in both COL11A2 and COL11A1 could predispose an individual to an increased risk of developing IVD degeneration [18]. VDR was the first reported gene associated with IVD degeneration in a Finnish study with alleles Taq1 and Fok1 polymorphism being associated with reduced signals on magnetic resonance Imaging (MRI) of thoracic and lumbar disc [29].

Within the AGC1 core protein, Chondroitin sulfate (CS) chains are present in two adjacent regions (CS1 \& CS2). The region coding for CS1 domain exhibits size polymorphism, known as variable number tandem repeats (VNTR). The functional property of aggrecan thus may vary between individuals with different lengths of the VNTR coding for the attachment sites of CS chains [30]. In the promoter region of human MMP-3 gene, a common polymorphism $5 \mathrm{~A} / 6 \mathrm{~A}$ was identified which may be implicated in IVD degeneration [19]. Cartilage intermediate layer protein (CLIP) is widely expressed in the IVDs and it increases in disc degeneration [20]. It localizes with TGF- $\beta 1$, inhibiting the TGF- $\beta 1$ mediated induction of ECM proteins such as aggrecan and collagen II. Functional genetic studies showed that the $C$ allele resulted in increased binding and inhibition of TGF- $\beta 1$, suggesting regulation of TGF- $\beta 1$ signaling by CLIP has a significant role in the etiopathogenesis of IVD degeneration [20]. As discussed above, IL-1 has regulatory roles in the neurological symptoms, metabolic changes and environmental factors in IVD degeneration. Association studies of a functional SNP of IL-1 $\beta$ is related to disc degeneration and LBP [14,16,31].
Although the advances in the genomic studies has highlighted the genetic factors with or without the presence of other risk factors e.g. ageing spine, the power of these studies has been poor since the sample sizes were not sufficient. The magnitude and mechanism of influence of the genetic factors on the development of IVD degeneration are still not fully understood [32]. Thus, to have a clear understanding the genetic modulation of IVD degeneration, well defined samples sharing similar environment and quantitative traits are strongly recommended [24]. If we can fully understand the molecular changes involved in IVD degeneration then creating targeted therapeutics based on genetic profiling becomes a possibility [18].

\section{Biomechanical effects of IVD degeneration}

Kirkaldy- Willis proposed a hypothesis that degeneration initially increases flexibility resulting in hypermobility in early IVD degeneration that leads to painful limitation of motion and eventually to tissue stiffening and decreased mobility in later stages of degeneration [33]. This hypothesis was affirmed later on in cadaveric biomechanical studies of spine motion. During flexion and bending motions increase to approximately grade IV of degeneration as the segment became unstable and flexibility decreased as the motion segment degenerated more to grade $\mathrm{V}$ [34]. Degeneration of the IVD and loss of endplate integrity lead to stress concentrations, loss of NP pressurization and a shift in comprehensive load carriage from NP to the AF tissues (esp. posterior AF) which is likely associated with damage to the AF or endplate $[35,36]$. The most constantly observed alteration in the structure of the IVD with degeneration is the well-known loss of IVD height [36]. IVD degeneration induces strong changes in the $\mathrm{AF}$ as well as the NP. It is well known that there is dramatic loss of water content in the NP which parallels loss of disc height. In the AF degeneration induces a significantly increased compressive modulus and decreased radial permeability which may be explained by the loss of water content, tissue compaction, structural remodeling and microfractures [37].

\section{Changes in cartilaginous end plate}

During aging, the cartilage end plate experience changes in proteoglycan and collagen content, resulting in gradual thinning and calcification [38-40]. When the spine is loaded, the bony end plate is subjected to high tensile strains as it deforms into the underlying trabecular bone [41]. The damage often occurs to the central area since they are thinner and supported by less dense trabecular bone. Focal weakness progress to circumferential fissures [42]. Endplate disruptions precipitates loss of uniform disc stress [43]. End plate disruptions may also impede nutrient transport to the cells within the nucleus of the disc or incite inflammatory responses in the disc or vertebra [44]. Endplate changes significantly increases diffusion (of small solutes like glucose, lactate and oxygen) between the vertebra and nucleus [45]. Various forms of end plate defects may be clinically associated with disc degeneration and axial back pain [46]. These defects include Schmorl nodes, fractures, avulsions/ erosions, and calcifications. Schmorl nodes are large, focal end plate indentations that represent herniations of nucleus into adjacent 
vertebrae and are associated with severity of disc degeneration [47]. Avulsions/erosions and calcifications are more common at the vertebral rim in the lumbar spine may be consequence of repeated trauma [48].

The role of end plate in chronic low back pain has been observed by provocative discography. MRI studies by Modic et al. [49] suggested three types of changes [49]. Type I changes (fibrovascular replacement) show decreased signal intensity on T1-weighted images and increased signal intensity on T2-weighted images. This coincides with disruption and fissuring of the end plate and vascularized granulation tissue within the marrow. Type II changes show increased signal intensity on T1-weighted images and an iso- or slightly hyperintense signal on T2-weighted images. This stage correlates with fatty marrow replacement. Both the types are dynamic changes which can revert to their previous stage [50,51]. Type III changes are represented by decreased signal intensity on both T1- and T2-weigthed images that correlate with dense woven bone (sclerosis) (Figure 1). It has been suggested that moderate to severe Modic Type I or II end plate abnormalities correlate $100 \%$ of the time with positive concordant pain at the adjacent disc [52].

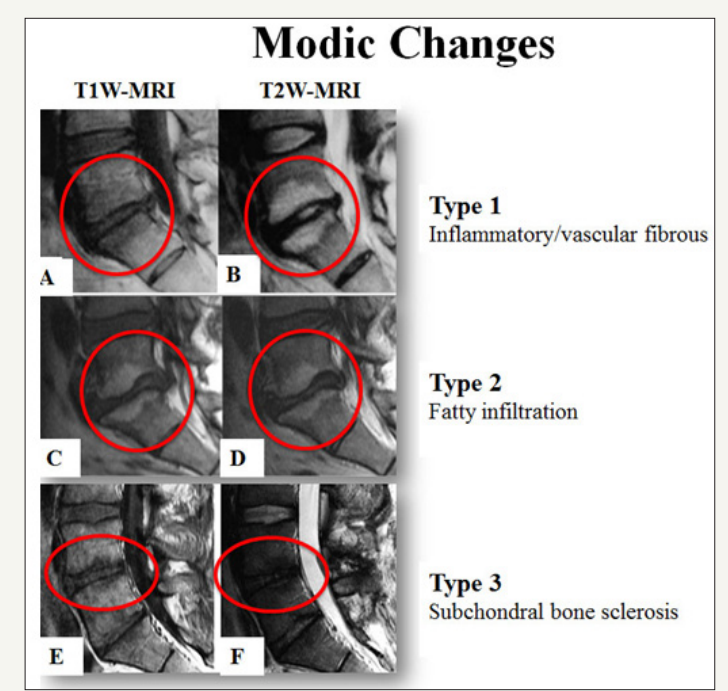

Figure 1: MRI of lumbar spine showing T1-W and T2-W images with types of Modic changes. (Talekar K, Maatta J, Karppinen J, Paananen M, Bow C et al. (2016) Refined phenotyping of Modic change: Imaging biomarkers of prolonged severe low back pain and disability. Medicine 95(22): e3495).

Evidence suggest that innervated end plate damage can be a source of chronic low back pain, its role in patients is likely underappreciated because innervated damage is poorly visualized with diagnostic imaging [53].

\section{Altered motion segment mechanics}

As the degeneration progresses, the resulting abnormal motion or instability is believed to be a competent cause of spinal pain, likely related to stretching of soft tissues and stimulation of free nerve endings $[33,54]$. The facet joints are one of the primary stabilizing structures of the spinal motion segment [55]. As the degeneration progresses, the anterior column support is lost leading to more weight being borne by the facet joints. The fulcrum of the motion segment moves dorsally to maintain balance [56]. As a result the load bearing patterns of the facet joints are altered [57].

IVDs motion segment behaviour is markedly changed due to the loss of AF integrity, loss of NP glycosaminoglycans and mild alterations in AF structure that induce laxity as well as endplate damage. IVD height loss may be the most sensitive variable affected by degeneration [58]. The laminated composite structure of IVDs is effective in inhibiting crack propagation and minimizes the effects of damage to the motion segments [59]. But the changes create a weaker biomechanical construct to resist the compression and shear forces. For herniation to occur through the AF, the IVD needs to be flexed or overloaded in multiple modes simultaneously. The likelihood of herniation to occur under higher load or higher loading rate [60]. Excessive torsion damages the neural arch and may cause delamination of the outer AF [61]. Complex loading in bending and compression can lead to radial fissures and disc prolapse either in a single loading cycle or by fatigue failure [62-64]. Axial rotation probably enhances the vulnerability of the posterior region of the IVD to damage and reduces the load required to cause disc failure [65].

\section{Pathogenesis of IVD degeneration}

Degenerative changes occur in a parallel manner at all three components of the spinal motion segment. As already mentioned earlier that the loss of aggrecan in the degenerate disc leads to low intra-discalosmotic pressure and the disc is unable to maintain hydration under axial loading. This influences the disc height leading to bulging of disc. The stress of load concentrates along the endplate and the AF [36]. The annular bulge results from less resistance against tension under load. These changes lead to abnormalities in the other components of the motion segment predisposing the disc to further damage (Figure 2). The circumferential tears progress to radial tears through which the nuclear materials can herniate into the perineural space. Disc disruption continues with a further loss of disc height. This leads to abnormal facet joint movements and a 
cascade of changes happen in these small joints. The degeneration goes through various stages i.e. synovitis followed by articular cartilage disruption, capsular laxity and joint subluxation. There is formation of hypertrophic osteophytes at the margins of the facet joints and periarticular fibrosis resulting in stiffness [65]. The ligamentum flavum buckles and facet joint overrides. The degenerate disc cannot respond adequately to the normal external load and the internal disc disruption continues. The damaged disc tries to repair itself but fails due to multiple internal factors which impair the healing response [65]. Kirkaldy -willis and Farfan had proposed three functional phases of degenerative disc disease: i) Temporary dysfunction without instability, ii) unstable phase, iii) stabilization following ligament calcification and osteophyte support [66].

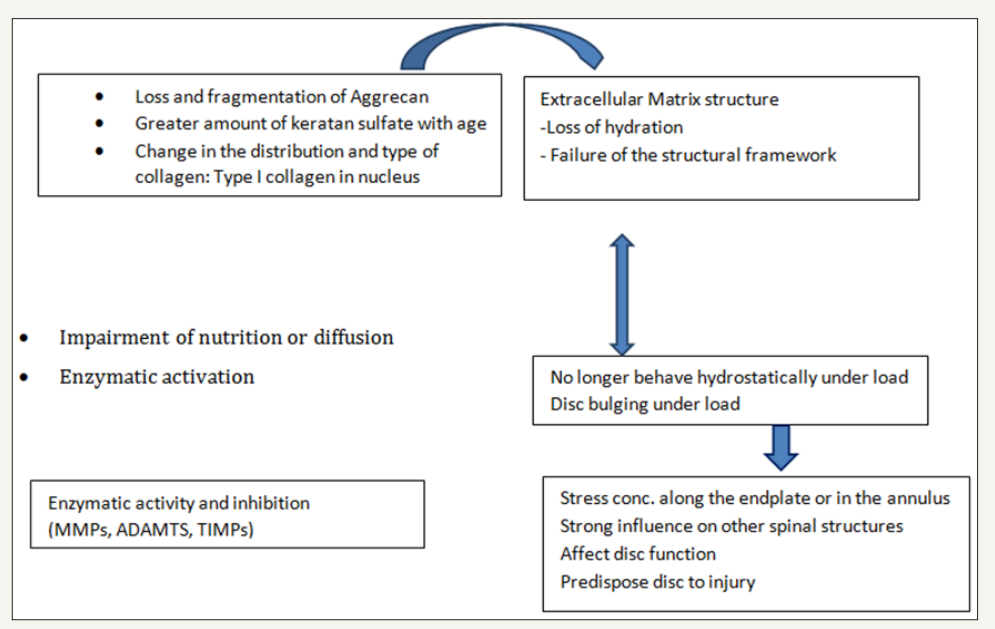

Figure 2: Diagrammatic representation of the spectrum of pathogenesis of the degenerative changes in the IVD (Courtsey Choi [65]).

\section{Grading of degenerative lumbar motion segment}

Degeneration of human IVD requires to be graded to investigate the relationship between morphology and functional parameters such as instability or to assess the correlation between different morphological changes e.g. facet joint degeneration. Of all the grading systems developed over the last 50years anatomical or histological or imaging studies, only few of these are recommended for use since their Kappa for interobserver reliability were $>0.60$ (discs) or $>0.40$ (facet joints) [67]. Since MRI imaging is the gold standard for assessing the lumbar spine pathologies in all patients with low back pain, we considered the two grading systems for practice. One by Pfirrmann et al. [68] for lumbar disc degeneration and the other by Weishaupt et al. [69] for lumbar facet joints (Table $2 \mathrm{a} \& \mathrm{~b})$.

Table 2a: Grading of lumbar disc degeneration on T2-W sagittal MRI scans by Pfirrmann et al. [68].

\begin{tabular}{|c|c|c|c|c|}
\hline Grade & Structure & $\begin{array}{l}\text { Distinction of Nucleus } \\
\text { and Annulus }\end{array}$ & Signal Intensity & Height of IV Disc \\
\hline I & Homogeneous, bright white & Clear & Hyperintense, isointense to CSF & Normal \\
\hline II & $\begin{array}{l}\text { Inhomogeneous with or w/o horizontal } \\
\text { bands }\end{array}$ & Clear & Hyperintense, isointense to CSF & Normal \\
\hline III & Inhomogeneous, grey & Unclear & Intermediate & $\begin{array}{l}\text { Normal to slightly } \\
\text { decreased }\end{array}$ \\
\hline IV & Inhomogeneous, grey to black & Lost & Intermediate to hypointense & $\begin{array}{l}\text { Normal to moderately } \\
\text { decreased }\end{array}$ \\
\hline $\mathrm{V}$ & Inhomogeneous, black & Lost & Hypointense & Collapsed disc space \\
\hline
\end{tabular}

Table 2b: Grading of lumbar facet degeneration using computed tomography and magnetic resonance imaging described by Weishaupt et al. [69].

\begin{tabular}{|c|c|}
\hline Grade & Facet Joint Changes \\
\hline 0 & Normal facet joint space (2-4mm width) \\
\hline 1 & Narrowing of facet joint space $(<2 \mathrm{~mm})$ and/or small osteophytes and/or mild hypertrophy of the articular process \\
\hline 2 & $\begin{array}{c}\text { Narrowing of facet joint space and/or moderate osteophytes and/or moderate hypertrophy of the articular process and/or mild } \\
\text { subarticular bone erosions }\end{array}$ \\
\hline 3 & $\begin{array}{l}\text { Narrowing of facet joint space and/or large osteophytes and/or severe hypertrophy of the articular process and/or severe } \\
\text { subarticular bone erosions and/or subchondral cysts }\end{array}$ \\
\hline
\end{tabular}




\section{Nature of discogenic pain}

The disc nociceptors generate amplified response called 'peripheral sensitization' [70]. The extruded nuclear material irritate the nerve roots and probably also the sinuvertebral nerve endings [71,72]. Degenerative changes in the IVD leads to abnormal loading of the annulus and can provoke mechanical stimulation. In the presence of inflammation of the joints the mechanically insensitive afferents can become active through secretion of proinflammatory mediators [73]. The presence of lactic acid leads to allow $\mathrm{pH}$ and stimulates the neurogenic and non-neurogenic pain mediator, provoking pain. In the degenerative disc disease inflammatory granulation tissue present in annular tears simulates 'peripheral sensitization' [74]. Substance P, Calcitonin gene related peptide and vasoactive intestinal polypeptide, neuropeptide Y, C -flanking peptide and synaptophysinimmunoreactive nerve fibres are present in the outer layers of AF [75]. Also there is abundant mast cells in the granulation tissue zones. These mast cells contribute to disc tissue inflammation, neovascularization, fibrosis formation, disc tissue degradation and secrete the nerve growth factor which may be a signaling substance such as TNF- $\alpha$ and IL-1 and play a role in the development of back pain [65].

Recent evidence suggest that the sensory nerve supply of the disc is similar to that of certain enteric structures and represents a form of visceral pain [76]. It is confirmed that a large proportion of nociceptive nerve fibres arising from the annulus of the lower lumbar discs pass through the sympathetic trunks in a non-segmental manner. This may be regarded as sympathetic sensory afferents. The peripheral endings of these nerves reveal a preponderance of calcitonin gene-related peptide-immunoreactive fibres $[77,78]$. These pain receptors are peripherally sensitized by the activity of sympathetic efferents [79]. It is suggested that these nociceptive afferents behave similarly to sympathetic afferents in enteric or visceral structures, which may initiate a pain impulse in response to ischaemia, pressure changes (mechanoreceptors) or inflammatory irritation [80]. The concept of 'central sensitization' of the descending autonomic nerves maybe a possibility due to stress which may lower the threshold of visceral afferents [81].

The lumbar intervertebral discs have been shown to be source of chronic low back pain without disc herniation in $26 \%$ to $42 \%$ $[82,83]$. Normally, one vertebral endplate has two nerve supplies: one enters the endplate along with perivertebral blood vessels, while the other that belongs to the sinuvertebral nerve branch that enters the endplate through the intervertebral foramen. The nerve density within the endplate is similar to that of the annulus, indicating that the endplate is also an important source of discogenic low back pain [84].

The natural history of discogenic back pain is that $90 \%$ of patients will experience improvement of their symptoms within 6weeks and resolution by 3 months with or without treatment and $20 \%$ will experience recurrent pain within 6 months $[85,86]$. The mechanism of radiculopathy related pain production has been of considerable debate. Compression of the nerve root is known to create edema formation and eventually lead to intraneural inflammation and hypersensitivity [87]. The nerve root is further sensitized mechanically and induce pain. Currently, the general consensus is a combination of mechanical and abnormal biochemical events is involved in the generation of radicular pain [88].

\section{Degenerative cascade (Figure $3 \mathrm{a} \& 3 \mathrm{~b}$ )}

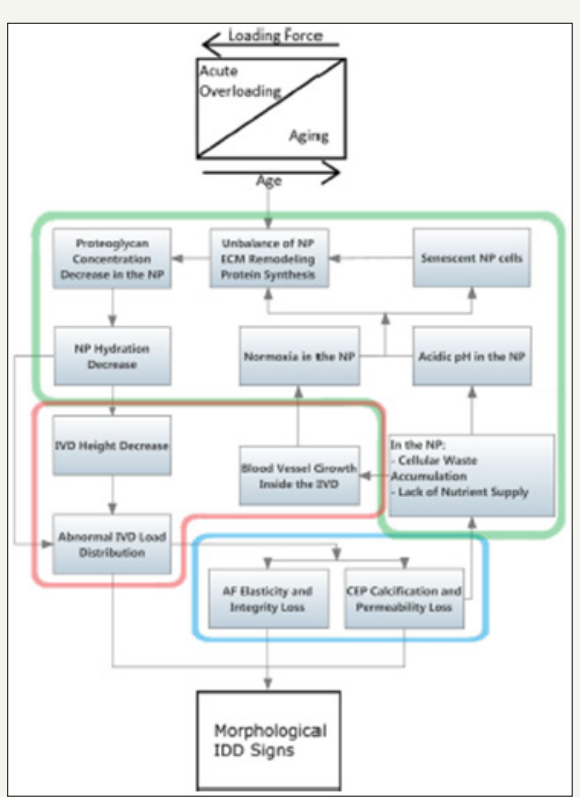

Figure 3a: Cascade of events associated with IVD degeneration disease (IDD) morphological signs. Starting by contribution of an acute or a repeated set of acute loading forces that as tissue aging progresses, become lighter to set IDD. The highlighted area divide events by tissue/groups of tissue - Red: IVD; Green: NP; Blue : AF and cartilaginous endplates. (Reproduced from van Uden S, Silva-Correis J, Oliveira JM, Reis RL. Current strategies for treatment of intervertebral disc degeneration: substitution and regeneration possibilities. Biomaterials Research 2017; 21: 4) 


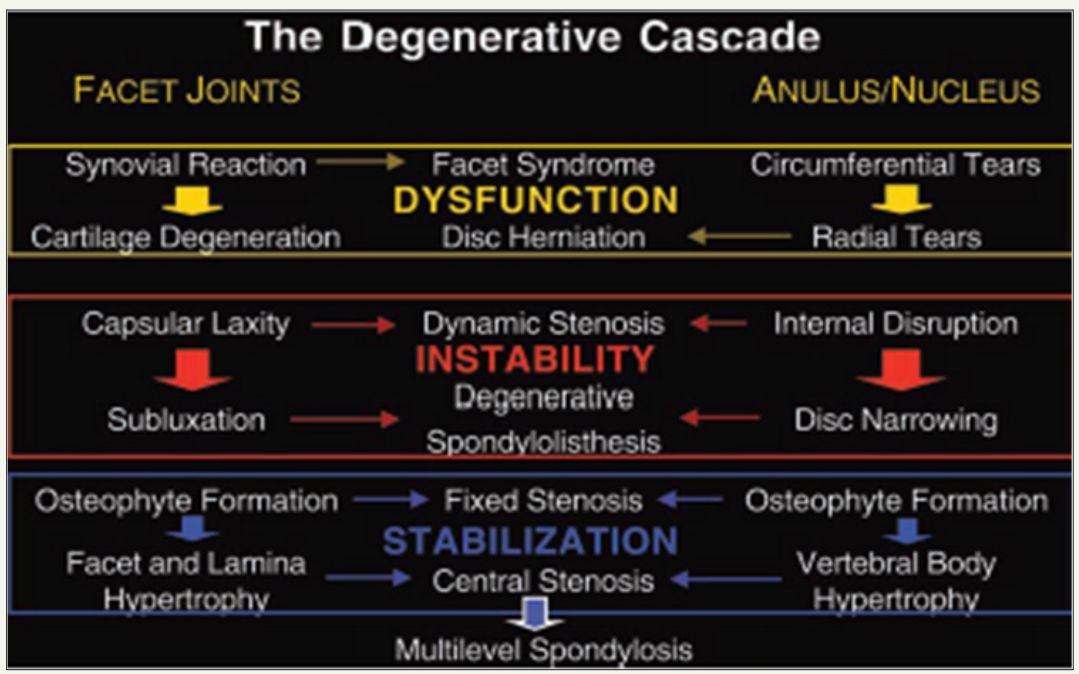

Figure 3b: The three basic stages of pathology and pathogenesis in the degenerative cascade of lumbar spondylosis and stenosis (Kim PK, Branch CL (2006) The lumbar degenerative disc: confusion, mechanics, management. Clin Neurosurg 53: p21)

The sequelae of degenerative disc disease are a series of interrelated events with three basic stages of patho-physiology i.e. dysfunction, instability and stabilization. By the third decade of life a disc reaches its full development and begins to degenerate. A degenerate disc may predispose an individual to higher risk of disc herniation and cause pain in an otherwise unpainful condition. The prevalence of a symptomatic herniated lumbar disc is about $1 \%$ to $3 \%$ with the highest prevalence among people aged 30 to 50 years, with a male to female ratio of 2:1.89-91In individuals aged 25 to 55 years, about $95 \%$ of herniated discs occur at the lower lumbar spine (L4/5 and L5/S1 level); disc herniation above this level is more common in people aged over 55 years [92,93]. In 95\% of the lumbar disc herniation the L4-L5 and L5-S1 discs are affected. Tears are most frequent postero-lateral where the annulus fibrosis is thin.

In the early stages of disc degeneration (dysfunction), the AF fibrillates and develops central cracks (internal disc disruption) which extend to the periphery. Bending or twisting of the lumbar spine may lead to radial tears and disc herniation. The facet joints develop synovitis with onset of cartilage degeneration. All these changes lead the motion segment to instability where the internal disc disruption continues leading disc narrowing. Facet joint capsular laxity with subluxation leads to stage of instability and a dynamic stenosis occurs. Continued desiccation and fibrosis leads to excessive narrowing of disc space leading to stiffness. Osteophytes develop leading to vertebral hypertrophy. Forward slippage of vertebrae or spondylolisthesis due to the segmental instability may further narrow the spinal canal and cause stenotic symptoms. Degenerative spondylolisthesis is common at $\mathrm{L} 4 / 5$ level.

Central disc bulging or herniation can produce spinal stenosis and present as neurogenic claudication. It is more often seen in the elderly who displays a constellation of symptoms including LBP and characteristic leg pain with walking or standing. Positions that flex the spine are able to slightly increase the canal diameter and therefore reduce the neural compression resulting in alleviation of symptoms. It is observed that neurogenic claudication may co-exist with lumbar radiculopathy in the event of concomitant foraminal stenosis.

\section{References}

1. Fitzell P, Hagg O, Jonsson D, Nordwall A, Swedish Lumbar Spine Study Group (2006) Cost-effectiveness of lumbar fusion and nonsurgical treatment for chronic low back pain in the Swedish lumbar spine study: a multicenter, randomized, controlled trial from the Swedish lumbar spine study group. Spine 29(4): 421-434.

2. Frank JW, Kerr MS, Brooker AS (1996) Disability resulting from occupational low back pain. Part I: what do we know about primary prevention? A review of the scientific evidence on prevention before disability begins. Spine 21(24): 2908-2917.

3. Miller J, Schamtz C, Schultz A (1988) Lumbar disc degeneration: correlation with age, sex and spine level in 600 autopsy specimens. Spine 13(2): 173-178.

4. Waddell G (1987) 1987 Volvo award in clinical sciences. A new clinical model for the treatment of low back pain. Spine 12(7): 632-644.

5. Samini F, Gharedhagi M, Khajavi M, Samini M (2014) The etiologies of Low back pain in patients with lumbar disc herniation. Iran Red Crescent Med J 16(10): 1-5.

6. Videman T, Battie MC (1999) The influence of occupation on lumbar degeneration. Spine 24(11): 1164-1168.

7. Hassett G, Hart DJ, Manek NJ (2003) Risk factors for progression of lumbar spine disc degeneration: the Chingford study. Arthritis Rheum 48(11): 3112-3117.

8. Slosar PJ, Perkins RB, Snook D (2002) Effects of cigarette smoking on the spine: a focused review. Spineline 111(6): 6-9.

9. Takaishi H, Nemoto O, Shiota M, Kikuchi T, Yamada H, et al. (1997) Type II collagen gene expression is transiently up regulated in experimentally induced degeneration of rabbit intervertebral disc. J Orthop Res 15(4): 529-538.

10. Freemont AJ, Watkins A, Le Maitre CL, Jeziorska M, Hoyland JA (2002) Current understanding of cellular and molecular events in intervertebral disc degeneration: implications for therapy. J Pathol 196(4): 374-379. 
11. Le Maitre CL, Pockert A, Buttle DJ, Freemont AJ, Hoyland JA (2007) Matrix synthesis and degradation in human intervertebral disc degeneration. Biochem Soc Trans 35(Pt4): 652-655.

12. Jones GC, Riley GP (2005) ADAMTS proteinases: a multi-domain, multifunctional family with roles in extracellular matrix turnover and arthritits. Arthritis Res Ther 7(4): 160-169.

13. Freemont AJ (2009) The cellular pathobiology of the degenerate intervertebral disc and discogenic back pain. Rheumatology (Oxford) 48(1): 5-10.

14. Le Maitre CL, Freemont AJ, Hoyland JA (2005) The role of interleukin-1 in the pathogenesis of human intervertebral disc degeneration. Arthritis Res Ther 7(4): 732-745.

15. Abe Y, Akeda K, An HS, Aoki Y, Pichika R, et al. (2007) Proinflammatory cytokines stimulate the expression of nerve growth factor by human intervertebral disc cell. Spine 32(6): 635-642.

16. Le Maitre CL, Hoyland JA, Freemont AJ (2007) Catabolic cytokine expression in degenerate and herniated human intervertebral discs: IL$1 \beta$ and TNF- $\alpha$ expression profile. Arthritis Res Ther 9(4): 77-87.

17. Yuan HY, Tang Y, Liang YX, Lei L, Xiaod GB, et al. (2010) Matrix metalloproteinase-3 and vitamin $\mathrm{d}$ receptor genetic polymorphisms and their interactions with occupational exposure in lumbar disc degeneration. J Occup Health 52(1): 23-30.

18. Martirosyan NL, Patel AA, Carotenuto A, Kalani MYS, Belykh E, et al. (2016) Genetic alterations in intervertebral disc disease. Front Surg 3 59.

19. Takahashi M, Haro H, wakabayashi Y, Kawa-uchi T, Kimori H, et al. (2001) The association of degeneration of the intervertebral disc with $5 \mathrm{a} / 6 \mathrm{a}$ polymorphism in the promoter of human matrix metallo-proteinase-3 gene. J Bone Joint Surg Br 83(4): 491-495.

20. Seki S, Kawaguchi Y, Chiba K (2005) A functional SNP in CLIP, encoding cartilage intermediate layer protein, is associated with susceptibility to lumbar disc disease. Nat Genet 37(6): 607-612.

21. Kepler CK, Ponnappan RK, Tannoury CA, Risbud MV, Anderson DG (2013) The molecular basis of intervertebral disc degeneration. Spine J 13(3): 318-330.

22. Fernandes I, Hampson G, Cahours X (1997) Abnormal sulfate metabolism in vitamin deficient rats. J Clin Invest 100(9): 2196-2203.

23. Lee JM, Song JY, Baek M, Jung HY, Kang H, et al. (2011) Interleukin-1 $\beta$ induces angiogenesis and innervation in human intervertebral disc degeneration. J Orthop Res 29(2): 265-269.

24. Chan D, Song Y, Sham P, Cheung KMC (2006) Genetics of disc degeneration. Eur Spine 15 (Suppl 3): S317-325.

25. Pluijm SM, van Essen HW, Bravenboer N, Uitterlinden AG, Smit JH, et al. (2004) Collagen type 1 alpha Sp1 polymorphism, osteoporosis, and intervertebral disc degeneration in older men and women. Ann Rheum Dis 63(1): 71-77.

26. Tilkeridis C, Bei T, Garantziotis S, Stratakis CA (2005) Association of a COL1A1 polymorphism with lumbar disc disease in young military recruits. J Med Genet 42(7): e44.

27. Mayer JE, Iatridis JC, Chan D, Qureshi SA, Gottesman O, et al. (2013) Genetic polymorphisms associated with intervertebral disc degeneration. Spine J 13(3): 299-317.

28. Paassilta P, Lohiniva J, Goring HH, Perala M, Raina SS, et al. (2001) Identification of a novel common genetic risk factor for lumbar disk disease. JAMA 285(14): 1843-1849.

29. Videman T, Leppavuori J, Kaprio J (1998) Iatrogenic polymorphisms of the vitamin D receptor gene associated with intervertebral disc degeneration. Spine 23 (23): 2477-2485.
30. Doege KJ, Coulter SN, Meek LM (1997) A human specific polymorphism in the coding region of the aggrecan gene. Variable number of tandem repeats produce a range of core protein sizes in the general population. J Biol Chem 272(21): 13974-13979.

31. Solovieva S, Leino Arjas P, Saarela J (2004) Possible association of interleukin 1 gene locus polymorphisms with low back pain. Pain 109(12): 626-633.

32. Feng Y, Egan B, Wang J (2016) Genetic factors in intervertebral disc degeneration. Genes Dis 3(3): 178-185.

33. Yong-Hing K, Kirkaldy-willis WH (1983) The pathophysiology of degenerative disease of lumbar spine. Orthop Clin North Am 14(3): 491504 .

34. Fujiwara A, Lim TH, An HS (2000) The effect of disc degeneration and facet joint osteoarthritis on the segmental flexibility of the lumbar spine. Spine 25(23): 3036-3044

35. Zhao F, Pollintine P, Hole BD, Dolan P, Adams MA (2005) Discogenic origins of spinal instability. Spine 30(23): 2621-2630.

36. Adams MA, McNally DS, Dolan P (1996) 'Stress' distributions inside intervertebral discs. The effect of age and degeneration. J Bone Joint Surg Br 78(6): 965-972

37.Gu WY, Mao XG, Rawlins BA (1999) Streaming potential of human lumbar annulus fibrosis's anisotropic and affected by disc degeneration. J Biomech 32(11): 1177-1182.

38. Roberts S, Menage J, Urban JPG (1989) Biochemical and structural properties of the cartilage end-plate and its relation to the intervertebral disc. Spine 14(2): 166-174

39. Bemick S, Caillet R (1982) Vertebral end plate changes with aging of human vertebrae. Spine 7(2): 97-102

40. Moore RJ (2006) The vertebral endplate: disc degeneration, disc regeneration. Eur Spine J 15 (Suppl 30): S333-337.

41. Fields AJ, Lee GL, Keaveny TM (2010) Mechanisms of initial endplate failure in the human vertebral body. J Biomech 43(16): 3126-3131.

42. Zhao FD, Pollintine P, Hole BD, Adams MA, Dolan P (2009) Vertebral fractures usually affect the cranial endplate because it is thinner and supported by less dense trabecular bone. Bone 44(2): 372-379.

43. Adams MA, Freeman BJ, Morrison HP, Nelson IW, Dolan P (2000) Mechanical initiation of intervertebral disc degeneration. Spine 25(13): 1635-1636.

44. Rajasekaran S, Babu JN, Arun R, Armstrong BR, Shetty AP, et al. (2004) ISSLS prize winner: a study of diffusion in human lumbar discs: a serial magnetic resonance imaging study documenting the influence of the endplate on diffusion in normal and degenerate discs. Spine 29(23): 2654-2667.

45. Pfirrmann CW, Resnick D (2001) Schmorl nodes of the thoracic and lumbar spine: radiographic-pathologic study of prevalence, characterization and correlation with degenerative changes of 1650 spinal levels in 100 cadavers. Radiology 219(2): 368-374.

46. Mok FP, samartzis D, Karppinen J, Luk KD, Fong DY, et al. (2010) ISSLS prize winner: prevalence, determinants, and association of Schmorl nodes of the lumbar spine with disc degeneration: a population based study of 2449 individuals. Spine 35(21): 1944-1952.

47. Modic MT, Steinberg PM, Ross JS, Masaryk TJ, Carter JR (1988) Degenerative disk disease; assessment of changes in vertebral body marrow with MR imaging. Radiology 166 (1Pt1): 193-199.

48. White AA, Panjabi M (1978) Clinical biomechanics of the spine Philadelphia: JB Lippincott Co., USA, pp. 1-18, 328-344, 459, 495, 502504,506 . 
49. Kuisma M, Karppinen J, Niinimaki J (2006) A three year follow up of lumbar spine end plate (Modic) changes. Spine 31(15): 1714-1718.

50. Marshman LA, Trewhella M, Freisem T, Bhatia CK, Krishna M (2007) Reverse transformation of Modic type 2 changes to Modic type 1 changes during sustained chronic low back pain severity. Report of two cases and review of literature. J Neurosurg Spine 6(2): 152-155.

51. Weishaupt D, Zanetti M, Hodler J (2001) Painful lumbar disc derangement: relevance of end plate abnormalities at MR imaging Radiology 218(2): 420-427.

52. Lotz JC, Fields AJ, Leibenberg EC (2013) The role of the vertebral end plate in low back pain. Global Spine J 3(3): 153-164.

53. Mimura M, Punjabi M, Oxland T, Crisco J, Yamamoto I, et al. (1994) Disc degeneration affects the multidirectional flexibility of the lumbar spine. Spine 19(12): 1371-1380.

54. Adams M, Hutton W (1983) The mechanical function of the lumbar apophyseal joints. Spine 8(3): 327-330.

55. Punjabi M, Goel V, Oxland T, Takata K, Duranceau J, et al. (1992) Human lumbar vertebrae. Quantitative three-dimensional anatomy. Spine 17(3): 299-306.

56. Fujiwara A, Lim T, An H, Tanaka N, Jeon C, et al. (2000) The effect of disc degeneration and facet joint osteoarthritis on the segmental flexibility of the lumbar spine. Spine 25(23): 3036-3044.

57. Iatridis JC, Nicoll SB, Michalek AJ, Walter BA, Gupta MS (2013) Role of biomechanics on intervertebral disc degeneration and regenerative therapies: What needs repairing in the disc and what are promising biomaterials for its repair? Spine J 13(3): 243-262.

58. Iatridis JC, AP Gwynn I (2004) Mechanisms for mechanical damage in the intervertebral disc annulus fibrosus. J Biomech 37(8): 1165-1175.

59. Wade KR, Robertson PA, Thambyah A, Broom ND (2014) How healthy discs herniate: a biomechanical and micro structural study investigating the combined effects of compression rate and flexion. Spine 39(13): 1018-1028.

60. Adams MA, Hutton WC (1981) The relevance of torsion to the mechanical derangement of the lumbar spine. Spine 6(3): 241-248.

61. Adams MA, Hutton WC (1983) The effect of fatigue on the lumbar intervertebral disc. J Bone Joint Surg Br 65(2): 199-203.

62. Adams MA, Hutton WC (1985) Gradual disc prolapse. Spine 10(6): 524 531.

63. Adams MA, Hutton WC (1982) Prolapsed intervertebral disc: a hyper flexion injury. Spine 7(3): 184-191.

64. Veres SP, Robertson PA, Broom ND (2010) The influence of torsion on disc herniation when combined with flexion. Eur Spine J 19(9): 14681478.

65. Choi YS (2009) Pathophysiology of degenerative disc disease. Asian Spine J 3(1): 39-44.

66. Kirkaldy-Willis W, Farfan H (1982) Instability of the lumbar spine. Clin Orthop 165: 110-123.

67. Kettler A, Wilke HJ (2006) Review of existing grading systems for cervical and lumbar disc and facet joint degeneration. Eur Spine J 15(6): 705-718.

68. Pfirrmann CW, Metzdorf A, Zanetti M, Hodler J, Boos N (2001) Magnetic resonance classification of lumbar intervertebral disc degeneration. Spine 26(17): 1873-1878.

69. Weishaupt D, Zanetti M, Boos N, Hodler J (1999) MR imaging and Ct in osteoarthritis of the lumbar facet joints. Skeletal Radiol 28(4): 215-219.
70. Brisby H (2006) Pathology and possible mechanisms of nervous system response to disc degeneration. J Bone Joint Surg Am 88 (Suppl 2): 68-71.

71. Kuslich SD, Ulstrom CL, Michael CJ (1991) The tissue origin of low back pain and sciatica: a report of pain response to tissue stimulation during operations on the lumbar spine using local anaesthesia. Orthop Clin North Am 22(2): 181-187.

72. Olmarker K, Blomquist J, Stromberg J (1995) Inflammatogenic properties of nucleus pulposus. Spine 20(6): 665-669.

73. Schaible HG, Schmidt RF (1985) Effects of an experimental arthritis on the sensory properties of the fine articular afferent units. J Neurophysiol 54(5): 1109-1122.

74. Burke JG, Watson RWG, McCormack D (2002) Intervertebral discs which cause low back pain secrete high levels of inflammatory mediators. J Bone Joint Surg Br 84: 196-201.

75. Konttinen YT, Gronblad M, Antti-Poika I (1995) Neurohistochemical analysis of peridiscal nociceptive neural elements. Spine 20: 928-35.

76. Takebayashi T, Cavanaugh JM, Kallakari S, Chen C, Yamashita T (2006) Sympathetic afferent units from lumbar intervertebral discs. J Bone Joint Surg Br 88: 554-557.

77. Morinaga T, Takahashi K, Yamagata M (1996) Sensory innervation to the anterior portion of lumbar intervertebral disc. Spine 21: 1848-1851.

78. Aoki Y, Ohtori S, Takahashi K (2004) Innervation of the lumbar intervertebral disc by nerve growth factor-dependent neurones related to inflammatory pain. Spine 29(10): 1077-1081.

79. Suseki K, Takahishi Y, Takahashi K (1996) CGRP-immunoreactive nerve fibres projecting to lumbar facet joints through the paravertebral sympathetic trunk in rats. Neurosci Lett 221(1): 41-44.

80. Ness TJ, Gebhart G (1990) Visceral pain: a review of experimental studies. Pain 41(2): 167-234.

81. Edgar MA (2007) The nerve supply of the lumbar intervertebral disc. J Bone Joint Surg Br 89(9): 1135-1139.

82. Manchikanti L, Singh V, Pampati V, Damron KS, Barnhill RC, et al. (2001) Evaluation of the relative contributions of various structures in chronic low back pain. Pain Physician 4(4): 308-316.

83. Schwarzer AC, Aprill CN, Derby R, Fortin J, Kine G, et al. (1995) The prevalence and clinical features of internal disc disruption in patients with chronic low back pain. Spine 20(17): 1878-1883.

84. Lotz JC, Ulrich JA (2006) Innervation, inflammation, and hypermobility may characterize pathologic disc degeneration: review of animal model data. J Bone Joint Surg Am 88 Suppl 2: 76-82.

85. Madigan L, Vaccafro AR, Spector LR, Milam RA (2009) Management of symptomatic lumbar degenerative disc disease. J Am Acad Orthop Surg 17(2): 102-111.

86. Cassidy JD, Cote P, Carroll LJ, Kristman V (2005) Incidence and course of low back pain episodes in the general population. Spine 30(24): 28172823.

87. Rydevik BL, Pedowitz RA, Hargens AR (1991) Effects of acute graded compression on spinal nerve root function and structure. An experimental study of the pig cauda equina. Spine 16(4): 487-493.

88. Saal JA (1996) Natural history and non-operative treatment of lumbar disc herniation. Spine 21 (Suppl 24): 2S-9S

89. Andersson G (1997) Epidemiology of spinal disorders. In: Frymoyer JW Ducker TB, Haider NM (Eds.), The adult spine: principles and practice. Raven Press, New York, USA, pp. 93-141.

90. Heliovaara M (1988) Epidemiology of sciatica and herniated lumbar intervertebral disc. Helsinki, The Social Insurance Institution, Finland. 
91. Postacchini F, Cinotti G (1999) Etiopathogenesis. In: Postacchini F (Ed.), Lumbar disc herniation. Springer-Verlag, New York, USA, pp. 151-64.

92. Friberg S, Hirsch C (1949) Anatomical and clinical studies on lumbar disc degeneration. Acta Orthopaedic Scandinavica 19: 222-242.
93. Schultz A, Andersson G, Ortengren R (1982) Loads on the lumbar spine. Validation of a biomechanical analysis by measurements of intradiscal pressures and my electric signals. J Bone Joint Surg Am 64(5): 713-720. (c) (i) Creative Commons Attribution 4.0

For possible submissions Click Here

Submit Article

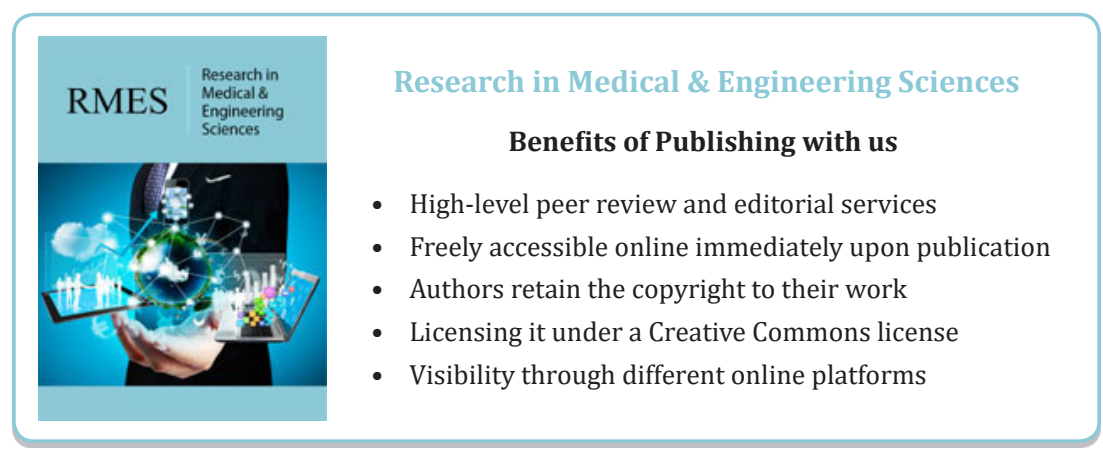

